\title{
Efeitos de Sentidos no Microdiscurso de Jingles Políticos
}

Effects of Senses in the Micro Discourse of Political Jingles

\author{
Ednéia Aparecida Bernardineli BERNINI* \\ Maria Célia Cortez PASSETTI**
}

Resumo: Este artigo tem como objetivo analisar o funcionamento discursivo dos jingles de sujeitos candidatos a governador do Estado do Paraná, nas eleições de 2010. Para subsidiar esta análise, recorre-se a leituras e a conceitos desenvolvidos no interior da Análise do Discurso e da Teoria da Comunicação. Para a Análise do Discurso, o sentido não está no texto, mas na relação que este mantém com quem o produz, com quem o lê, com outros textos e com outros discursos possíveis. Dessa forma questiona-se como o interdiscurso sustenta a construção da imagem (ethos) dos sujeitos candidatos, mostrando os efeitos de sentidos produzidos pelos jingles. Das análises dos seis jingles dos dois candidatos mais bem votados nas eleições ao governo paranaense, verificou-se que os jingles constroem um ethos positivo para os candidatos construído por efeitos de sentidos específicos decorrentes das condições de produção desse momento sócio-histórico e dessa campanha política. Os dois candidatos se confrontaram basicamente pelos ethé de identificação entre um candidato continuísta e um inovador. Todavia a temática em si não é inovadora e parte de imaginários tradicionais. Portanto, percebe-se nos jingles a projeção do eleitor-alvo do candidato em sua busca pelo voto.

Palavras-chave: Discurso político. Jingles. Candidato a governador do Paraná.

* Mestre em Linguística Aplicada pela Universidade Estadual de Maringá (2003). Atualmente é Professora da rede pública de educação básica do Paraná. Contato: edneiaabbernini@hotmail.com

** Doutora em Letras pela Universidade Estadual Paulista de Assis (2002). Professora Associada da Universidade Estadual de Maringá. Contato: passetti@wnet.com.br 
Abstract: This work aims to analyze the discursive functioning of jingles of subject-candidates to the government of the state of Paraná in the 2010 elections. To subsidize this analysis, readings and concepts developed in Discourse Analysis and the Theory of Communication were used. For the Discourse Analysis the sense is not in the text, but in the relation that this maintains with whom produces it, reads it, with other texts and other possible discourses. This way, we question how the interdiscourse supports the construction of the subject-candidates' image, showing the effects of senses produced by the jingles. Analyzing six jingles from the most voted candidates in the elections for the government of Paraná, we verified that the jingles build a positive ethos made by specific effects of senses deriving from production conditions of this social-historic moment and this political campaign. Both candidates confronted basically by the identification ethé between a continuing and an innovator candidate. However, the theme itself is not innovator and arises from traditional imaginaries. Thus, the jingles showed the projection of the elector-target of each candidate in search of votes.

Key-words: Political discourse. Jingles. Candidate to Government of Paraná.

\section{Introdução}

Neste artigo, propõe-se uma análise discursiva de jingles dos candidatos ao governo do estado do Paraná em 2010. Salienta-se que a seleção deste assunto se justifica em virtude do caráter persuasivo-argumentativo que esse gênero composto por uma materialidade verbo-musical desempenha numa campanha visando à adesão do voto dos eleitores, e da carência de estudos discursivos dentro de uma perspectiva voltada à compreensão de seu papel como elemento sintetizador de efeitos de sentidos que uma dada campanha deseja fixar nos eleitores. Buscar-se-á apresentar o discurso, como propõe Pêcheux, como um objeto sócio-histórico em que o linguístico está pressuposto, instaurando efeitos de sentido entre interlocutores, permeados por uma ideologia.

Para esta análise, alguns questionamentos foram formulados, instigados pela teoria da Análise do Discurso e pela Teoria da Comunicação e, para ancorar teórica e metodologicamente, recorre-se a leituras e a conceitos desenvolvidos pelos seguintes autores: Pêcheux (1999, 2008, 2009), Orlandi 
(1995), Achard (1999), Rubim (2000), Charaudeau (2006), Courtine (2006, 2009), Baronas (2007).

Primeiramente, definimos jingle de acordo com o Dicionário de Comunicação (RABAÇA; BARBOSA, 1987, p. 345) como uma "Mensagem publicitária em forma de música geralmente simples e cativante, fácil de cantarolar e de recordar". Inicialmente, o jingle era feito exclusivamente para um produto ou empresa, porém, hoje, em função dos custos com licenças de músicas, muitas empresas redescobrem o jingle como uma forma mais barata de produzir seus comerciais e destacar sua marca. Além dos jingles para empresas, podem-se encontrar também músicas para políticos, festas, datas comemorativas, campanhas de conscientização, entre outros. $\mathrm{O}$ uso dessa palavra inglesa em publicidade provém da canção de Natal norteamericana Jingle Bells.

Ainda, de acordo com o mesmo dicionário: "Sua duração média varia de 15 a 30 segundos. É normalmente gravado em disco ou em fita magnética (para transmissão em rádio) ou inserido na trilha sonora de filmetes para televisão e cinema, acompanhado de texto (locução) e imagem." (RABAÇA; BARBOSA, 1987, p. 345).

Luis Dolhnikoff (2010), ao referir-se aos jingles dos candidatos à sucessão presidencial, afirma:

Os jingles [...] são peças importantes de sua propaganda eleitoral, pois servem ao menos a três propósitos: ser o fundo musical das peças de TV, o marco musical das peças de rádio e, principalmente, o microdiscurso político mnemônico da campanha, ou seja, a síntese verbal memorizável da candidatura.

Convém ressaltar que os jingles dos candidatos podem ser considerados uma estratégia eleitoral e seu emprego nas mídias, em especial na televisão, juntamente com imagens que reforçam o conjunto de enunciados, por meio dos horários políticos, visa a atingir um maior número de eleitores, pois se tornam um gênero textual com fortes características de interação entre o candidato e o eleitor, de forma animada e descontraída.

Após ter contato prévio com o material disponível na internet, foram selecionados três jingles de dois candidatos favoritos a governador do Paraná nas eleições de 2010: Beto Richa e Osmar Dias. 


\section{Considerações Teóricas}

Como a interpretação de um fato discursivo não se reduz ao nível dos enunciados que o compõem, é necessário relacionar fatores como o interdiscurso, ou a memória discursiva, entendido como a rede de sentidos a qual um discurso se filia ou com a qual mantém relações diversas, a ideologia, como fato de interpretação em que se confrontam o simbólico e o político (ORLANDI, 1990, p. 36) e, portanto, questões de poder. Assim, por exemplo, quando um candidato se apresenta na propaganda eleitoral, seu discurso está atravessado por outros discursos que definem como o candidato compreende a sociedade e como deseja articular seu discurso junto aos eleitores.

Para o candidato, o período de campanha eleitoral exige uma maior interação dele com o eleitor, uma troca de 'intenções'. O eleitor quer que seus interesses sejam atendidos. O candidato, por sua vez, quer o voto e, para isso, deseja apresentar-se como o melhor porta-voz das propostas, procurando atender aos temas que estão previstos na agenda política. Esses temas, por vezes, repetem-se de um partido a outro e, em outras, o candidato procura falar daquilo que não foi frisado por outros partidos. Mostrar-se-á que essa interação e essa troca ficam marcadas nos jingles em análise.

Para o candidato, o eleitor não é meramente um ouvinte, mas um sujeito que reage diante dos programas eleitorais. Por esse motivo é que os candidatos tentam criar vínculos e afinidades com o eleitor. Diante disso, formula-se a hipótese de que o eleitor seja visto como o foco central das estratégias com as quais o candidato trabalha, precisando, pois, aproximar-se do eleitor (daquilo que este espera de um candidato) a fim de beneficiar-se com o voto. Espera-se que os jingles possibilitem essa afinidade e aproximação com o eleitor.

No discurso político eleitoral, o sujeito fala a partir do lugar discursivo de candidato a um dado cargo ou função e, nesse sentido, procura mostrar-se como o melhor porta-voz para a situação de bem estar a ser alcançada. Objetiva-se mostrar, então, como são organizados os jingles desses candidatos, para atingir seus fins eleitorais. Dentro de novas regras políticas, as vantagens, comumente oferecidas aos eleitores (tais como brindes, camisetas, bonés, chaveiros, canetas) hoje são proibidas, restando ao candidato buscar outras formas de comunicação e persuasão, sendo o jingle, cada vez mais utilizado e aperfeiçoado. 
A partir dessas considerações, é importante destacar as relações de poder que se fazem presentes nos discursos veiculados durante as propagandas eleitorais gratuitas na televisão, das quais os jingles fazem parte e, com isso, auxiliar o telespectador a assistir à referida programação com um olhar crítico.

O trabalho de análise implica a teorização da interpretação do discurso que visa também a uma descrição do que o discurso diz, buscando-se ouvir aquilo que ele não diz, mas que, do mesmo modo, constitui seus sentidos. Além disso, a noção de formação discursiva permite compreender o processo de produção de sentidos, sua relação com a ideologia e proporciona ao analista a possibilidade de estabelecer regularidades no funcionamento do discurso. Para Pêcheux (2009), formação discursiva é tudo aquilo que pode e deve ser dito, a partir de uma posição social determinada, inserida em um espaço de luta de classes. Assim, as palavras mudam de sentido ou adquirem um sentido dependendo da posição de quem as proferir, as palavras não portam um sentido em si mesmas, mas o sentido é determinado pelas posições ideológicas envolvidas no processo sócio-histórico do discurso.

Ele ainda propõe uma articulação entre formação discursiva e gênero do discurso, já que essa articulação possibilita mostrar que uma formação discursiva possui uma autonomia dependente tanto das classes a partir das quais são produzidas, quanto do gênero, pois aquilo que 'pode e deve ser dito' dependerá tanto do gênero discursivo quanto do posicionamento ideológico a qual o sujeito pertence. Para esse autor, gênero e posicionamento são "elementos essenciais no fornecimento das condições que possibilitam a irrupção das discursividades, inserindo-as numa ordem do enunciável" (PÊCHEUX, 2009, p.180).

Ao se introduzir a noção de história na Análise do Discurso, há a reflexão sobre questões de poder e das relações sociais, pois como afirma Charaudeau (2006, p. 17) "todo ato de linguagem está ligado à ação mediante as relações de força que os sujeitos mantêm entre si”. Em Pêcheux (2010) o discurso é definido não como transmissor de informação, mas como 'efeitos de sentido’ entre os locutores mediante relação de sentidos estabelecida por eles em um contexto social e histórico.

Courtine (2006, p. 15), ao resgatar a história da Análise do Discurso, afirma que "a AD não constitui simplesmente uma aparelhagem técnica" para uma prática de leitura, inicialmente voltada para textos políticos, mas é igualmente um modo de intervenção política. Assim, não se pode 
simplesmente ouvir um jingle político e não pensá-lo criticamente como uma das estratégias de intervenção de cada partido.

Ademais, na Análise do Discurso deve-se levar em conta o silêncio. Este é apresentado por Orlandi (1995, p. 13) como “a 'respiração' (o fôlego) da significação; um lugar de recuo necessário para que se possa significar, para que o sentido faça sentido.". Ainda para Orlandi (1995, p. 23), "Se a linguagem implica silêncio, este, por sua vez, é o não-dito visto do interior da linguagem. Não é o nada, não é o vazio sem história. É silêncio significante.". Essa ideia é reforçada no momento em que a autora diferencia silêncio e implícito, pois para ela "Ele [o silêncio] não remete ao dito, ele se mantém como tal, ele permanece silêncio e significa." (ORLANDI, 1995, p. 68). Assim, o silêncio não tem relação de dependência com as palavras, ele não depende das palavras para significar. Por meio dos jingles, ao dizer algo, outros sentidos possíveis são apagados, são silenciados.

Courtine (2006, p. 88) reforça que memória e esquecimento não podem ser dissociados no modo de enunciação do discurso político, visto que "na política, a memória é um poder: ela funda uma possibilidade de se exprimir, ela abre um direito à fala". Em relação ao poder, Rubim (2000) afirma que este emerge como relação de força, como prática que se exerce em disputa, como uma capacidade de levar o outro a realizar o que se deseja através da utilização de variados recursos; poderes esses que perpassam todas as relações sociais, em poderes específicos, tais como o poder político, o econômico, o militar, o simbólico, entre outros, dependendo dos recursos utilizados. Essas relações de poder podem ser realizadas como força material - violência, coerção; e como força simbólica - convencimento, coesão. No caso dos jingles, essa relação de poder se dá como força simbólica, pois se busca o convencimento e adesão para se votar no candidato específico, exaltado pelo jingle.

Rubim (2000) destaca dois grandes poderes em uma de suas obras, cujo título recebe o nome desses poderes "Comunicação e Política", sendo que nesta disputa entre esses poderes há o predomínio de um sobre o outro, mas não apenas como conflito, mas como complementariedade, "como campos que necessitam interagir com o(s) outro(s) campo (s) para se efetivar socialmente." (RUBIM, 2000, p. 14). Esse autor defende a ideia de que a sociedade é estruturada e ambientada pela mídia. Logo, a comunicação que era vista como um instrumento da política não é mais vista assim, pois há uma nova configuração da sociabilidade, em função da mídia, composta 
pelo 'espaço eletrônico', a 'televivência' e a 'globalização'. Essa sociedade estruturada e ambientada pela mídia faz emergir novas estratégias políticas, estratégias político-midiáticas. Os jingles são exemplos dessas novas estratégias políticas, como recurso da comunicação midiática, por meio do rádio e da televisão.

Numa visão pragmático-discursiva, Charaudeau (2006, p. 78) apresenta estratégias do discurso político, sendo uma delas uma boa construção discursiva do ethos, ou seja, da imagem que o político cria de si para os outros - o pathos. De acordo com esse mesmo autor, o "sentido veiculado por nossas palavras depende ao mesmo tempo daquilo que somos e daquilo que dizemos. O ethos é o resultado dessa dupla identidade, mas ele termina por se fundir em uma única." (CHARAUDEAU, 2006, p. 155) e se reagrupam em duas grandes categorias: o ethos de credibilidade e o ethos de identificação. Para a construção desse ethos, há vários procedimentos discursivos (CHARAUDEAU, 2006, p. 167) que não podem ser confundidos com as técnicas empregadas pelo marketing político. Buscar-se-á pelos jingles de cada candidato a presença dos ethé desses sujeitos políticos.

\section{Análises dos Jingles de Candidatos a Governador do Paraná em 2010}

Para este artigo, foram selecionados e transcritos três jingles de cada candidato. Eles estão disponíveis no site Youtube ou, ainda, no caso de Beto Richa, em áudio no site do próprio candidato. No entanto, não foram localizados os nomes dos autores ou agências criadores desses jingles. As imagens que acompanham esses jingles não serão analisadas, visto que, para um jingle, há mais de uma possibilidade de vídeo. Logo, esta análise se deterá ao enunciado verbal, sem desconsiderar que há aí também efeitos sonoros musicais importantíssimos na constituição de sua materialidade discursiva.

\subsection{Análise dos jingles do candidato Osmar Dias}

Jingles do Candidato Osmar Dias 


\section{Vamos Paraná, Vamos! $!^{1}$}

Nossa terra é nossa vida, sempre é tempo de plantar, essa gente de coragem construiu o Paraná. Vai embora violência, pode entrar educação, Vem saúde e segurança em respeito ao cidadão,

Refrão: Vamos Paraná, vamos / Vamos com Osmar, vamos / Vamos que vamos, vamos que vamos./ Vamos!!!

Pedro, Ana, Zé, Maria, Marcos, Clara e João, Paraná é uma família e merece proteção. É no campo é na cidade, gente de todo lugar, Paraná no rumo certo caminhando com Osmar. / Refrão.

II. Meteoro da Paixão ${ }^{2}$

Refrão: Vamos juntos com o Osmar pra ganhar a eleição / vote 12, vote Osmar / Meteoro da Paixão / Explosão de sentimentos pelo nosso Paraná / ah, no Osmar pó votar /

Quem vota Dilma, vota Osmar / Essa é a hora da união / Osmar é mais experiência, é amor no coração / tem a força que precisa pra cuidar do Paraná, ah no Osmar vamos votar /

Refrão.

\section{Pó votá no Osmar ${ }^{3}$}

Nóis é do tipo animado / Paranaense esforçado / já temo um cara porreta pra votar / nóis tamo do mesmo lado / Vamos se unir pelo estado / Vamo votá no Osmar / Osmaré do meu povão / conhece todo esse chão / vai ter jeitão arretado pra governar / Vamo que vamo Osmar / Vamo que vamo ganhá / Vamo junto com o Paraná / Pó votá / pó votá no Osmar, pó votá / voto aqui, voto lá no Osmar / Vamo Paraná, votá no Osmar.

Ao afirmar "Paraná no rumo certo caminhando com Osmar" reforça-se o efeito de sentido de continuidade, visto que o candidato Osmar Dias era apoiado pelos candidatos da situação, Requião, que renunciou ao cargo de

${ }^{1}$ Disponível em: <http:/ /www.youtube.com/watch?v=47nsz2a7kJs $>$. Acesso em: 12 dez. 2010.

2 Disponível em: < http:/ / www.youtube.com/watch?v $=u L W x x 8 z P w Z w>$. Acesso em: 12 dez. 2010.

${ }^{3}$ Disponível em: <http://www.youtube.com/watch?v=4Po4hDJwDog\& feature $=$ related $>$. Acesso em: 12 dez. 2010. 
governador para concorrer ao Senado, e Dilma, candidata à presidência da República, sucessora do presidente Luis Inácio Lula da Silva. Ao propor que o processo político continue, há uma relação interdiscursiva com o título do jingle da presidência, que era "Sem Medo de ser Feliž" de Wagner Tiso. Ao relacionar os títulos dos dois jingles tem-se: 'Vamos Paraná sem medo de ser feliz', sem medo de continuar feliz, por isso está no "rumo certo", por isso a continuidade e a não mudança para um "Novo Paranâ", como propõe o outro candidato. Em "Quem vota Dilma, vota Osmar / Essa é a hora da união" pressupõe como objetivo atingir os eleitores da candidata à presidência, tem-se a produção de efeito de evidência, que anularia a possibilidade de alguém votar em Dilma e em Richa. Esse candidato utilizase do governo do presidente para se promover e, com isso, faz, ainda, uma propaganda à candidata a presidente. Há a presença do continuísmo ao trazer à cena tudo o que o governo Lula representou. Retoma, também, a coligação entre os partidos de ambos - PT e PDT -, e que seria muito bom para o Paraná se ambos fossem eleitos, confirmado ainda por "tem a força que precisa pra cuidar do Paraná", que cria efeitos de sentido remetendo a essa união, ao apoio que seria recebido, mas também a 'coragem' do candidato para governar.

Em "Vai embora violência, pode entrar educação" há uma forma de silêncio (ORLANDI, 1995), pois, ao apresentar violência e educação, campos distintos que se relacionam, reforça-se a ideia de que, se houver investimentos em educação, haverá segurança, paz e tranquilidade, logo, não haverá violência. Confirma-se, assim, que o "dizer e o silenciamento são inseparáveis: contradição inscrita nas próprias palavras” (ORLANDI, 1995, p. 76).

Em "Nossa terra é nossa vida, sempre é tempo de plantar" e "É no campo é na cidade, gente de todo lugar" há uma retomada da formação e origem do candidato, por ser ele um engenheiro agrônomo e agricultor, bem como um direcionamento ao eleitorado tanto da zona rural quanto da zona urbana. O eleitor da zona rural também é marcado em: "Nóis é do tipo animado / Paranaense esforçado / já temo um cara porreta pra votar / nóis tamo do mesmo lado / Vamos se unir pelo estado / Vamo votá no Osmar / Osmar é do meu povão / conbece todo esse chão / vai ter jeitão arretado pra governar". Esperava-se, inclusive, em vez de "Vamos se unir pelo estado" - 'Vamo se uni pelo estado', bem como 'temo um cara porreta pra votá' e 'vai tê jeitão arretado pra governá', características do falar popular, rural, simples. Entretanto, precisa-se considerar também a preocupação com as rimas, pois, nas ausências do /r/ nos finais 
dos verbos de primeira conjugação, estes passam a ser oxítonas rimando com Paraná e, nos momentos em que aparece o /r/, este rima com Osmar: votar, governar, ganhar. Ainda em "Pedro, Ana, Zé, Maria, Marcos, Clara e João, Paraná é uma família e merece proteção. É no campo é na cidade, gente de todo lugar", há a tentativa de não perder nenhum voto e, também, de mostrar a igualdade entre campo e cidade; homens e mulheres, já que, por tradição, há essa separação ou exclusão entre uns e outros. Inclusive por este candidato ter fama de ser mais rural, o jingle amplia o leque de identificação com novos eleitores.

Ao afirmar "Osmar é mais experiência", fica determinado seu período de atuação em cargo público desde 1983, em oposição ao candidato rival, mais jovem e que iniciou no campo político em 1992. Pressupõe-se aqui uma memória coletiva que domina esse conhecimento; não exatamente os anos em que iniciaram suas experiências políticas, mas sim, um período maior de atuação política, em função, inclusive, da própria idade dos candidatos, o mais velho é um sujeito político com mais experiência. Para Pêcheux (1999, p. 52) "a memória tende a absorver o acontecimento" como "um jogo de força na memória, sob o choque do acontecimento", ou seja, o sujeito político Osmar Dias é mais velho, tem mais experiência política, logo merece o voto dos eleitores, que não podem se arriscar ao 'novo'. Ao eleitor é transmitida a ideia de que este candidato tem um passado que o embasa e legitima.

Esse discurso, o da experiência, produz o efeito de um candidato que, já dotado de um saber-fazer e de um poder-fazer 'comprovados', apenas precisa da legalidade, proveniente do voto, para assumir a função pública. Trata-se, portanto, de pressupor e de apresentar uma capacidade, com vistas a conquistar a credibilidade e a legitimidade.

Em "Pedro, Ana, Zé, Maria, Marcos, Clara e João, Paraná é uma familia e merece proteção", há uma metáfora considerando o estado do Paraná como uma família e, se esta merece proteção, o Paraná também. Ao considerar o eleitor conivente com esse pensamento, como se todos pertencessem à mesma família, busca-se credibilidade junto aos paranaenses em forma de voto. Isso se confirma pelos nomes de pessoas citadas que representam todos os eleitores paranaenses, componentes dessa grande família. Além disso, em "Nossa terra é nossa vida, sempre é tempo de plantar, essa gente de coragem construiu o Paranâ', 'essa gente' seriam os paranaenses que já construíram um Paraná, não precisando de algo novo, de 'um novo Paraná', mas de continuar plantando: 'sempre é tempo de plantar'. 


\subsection{Análise dos jingles do candidato Beto Richa}

\section{Novo Paraná ${ }^{4}$}

Nessa terra, onde faço minha vida / Semeada de conquistas / Pra gente se orgulhar

Um novo tempo / Vai marcar a nossa história / Vai abrir novos caminhos / É assim que vai nascer

Refrão: Um novo Paraná / É o que a gente quer / Um novo Paraná / É o que a gente faz. / Um novo Paraná / Com Beto Richa / A gente pode mais (duas vezes) / Beto Richa

\section{Quero Beto Richa ${ }^{5}$}

Um novo jeito de governar / Ouvindo o que o povo quer / Novas ideias, um novo olhar / É Beto Richa, eu boto fé / Tem coragem e experiência / Richa é filho desse chão / Tem história e competência pra mudar a direção /

Refrão: Ah, Paraná, se enche de orgulho e veste essa camisa / ah, Paraná, pra governador, en quero Beto Richa /

Mais trabalho e transparência / Agora é hora de crescer / Nasce um novo Paraná / feito por mim e por você /

\section{O Paraná agora é Beto ${ }^{6}$}

Refrão: O Paraná agora é Beto eu também sou, Todo mundo tá com Beto eu também tô, quero Beto Richa, meu governador!

O Paraná está mudando, Tá soprando um outro vento, pra andar pra frente, pra cuidar da gente, um novo tempo, Tempo de ideias novas, Tempo de mais confiança, Tempo de trabalho, tempo de união, tempo de esperança. É Beto Richa pra crescer em paz, É Beto Richa já mostron que faz, É Beto Richa porque o Paraná tá querendo mais...

Refrão:

É Beto Richa pra crescer em paz, É Beto Richa já mostrou que faz, É Beto Richa porque o Paraná tá querendo mais...

${ }^{4}$ Disponível em: <http://www.youtube.com/watch?v=xIv33Fgk-hM\&NR=1>. Acesso em: 12 dez. 2010.

${ }^{5}$ Disponível em: <http://www.betoricha.com.br/multimidia>. Acesso em: 12 dez. 2010.

${ }^{6}$ Disponível em: <http://www.youtube.com/watch?v=Jx4ae-eAR34>. Acesso em: 12 dez. 2010. 
Ao afirmar, nos jingles, “O Paraná está mudando, Tá soprando um outro vento, pra andar pra frente, pra cuidar da gente, um novo tempo, Tempo de ideias novas, Tempo de mais confiança, Tempo de trabalho, tempo de união, tempo de esperança" ; "Um novo jeito de governar / [...] Novas ideias, um novo olhar"; "Nasce um novo Paraná" e "Um novo tempo [...] Vai abrir novos caminhos / É assim que vai nascer Um novo Parană" (grifos nosso), resgata-se a ideia do novo, de eleger-se um novo candidato, inclusive mais jovem, produzindo o apagamento da administração anterior; marcada pela ideologia de oposição, pede mudança e ideias novas para instaurar-se um “novo Paranâ". Nos três jingles aparece a ideia do novo vindo à tona, com o sentido de que as mudanças não o assustam. Viver nesta sociedade dinâmica é um desafio e faz com que as pessoas tenham que sair de sua zona de conforto, surge a oportunidade de mudança, de ideias novas. Esse fator se torna importante para a evolução da sociedade; o novo não propicia medo e os eleitores são convocados a ter essa atitude corajosa de querer o novo, de querer "andar pra frente"; no plano de governo do candidato, em vários momentos, aparece a proposta para esse "Novo Paraná". E é por essa relação de forças (oposição x situação; novo x velho; mudança x continuidade) que se instaura o confronto entre os dois candidatos, políticos que representam partidos 'rivais'.

Ao afirmar "Beto Richa já mostrou que faz". e "Um novo jeito de governar / Ouvindo o que o povo quer" desloca-se o discurso para a administração desse candidato no momento em que fora prefeito de Curitiba, pois atendia a população curitibana para ouvi-la, denominada de 'democracia participativa'; portanto, a memória é "reconstruída na enunciação". "A enunciação, então, deve ser tomada, não como advinda do locutor, mas como operações que regulam o encargo, quer dizer a retomada e a circulação do discurso" (ACHARD, 1999, p. 17).

Em "Tem coragem e experiência / Richa é filho desse chão / Tem história e competência pra mudar a direção" resgata-se o fato de Richa ser realmente paranaense, ser filho de ex-governador do Paraná José Richa, ter nascido em Londrina-PR, o que não ocorre com seu adversário, Osmar Dias, que nascera em Quatá-SP, mas, para isso fazer sentido, é preciso acionar a memória discursiva dos paranaenses no momento de ouvir esse jingle.

Em "Todo mundo tá com Beto eu também tô, [...] É Beto Richa porque o Paraná tá querendo mais..." pode-se fazer um resgate da memória social política, pois o jingle de Dilma, candidata à presidência da República do partido adversário apresenta "Lula tá com ela / Eu também tô / Veja como o Brasil já 
mudou / Mas a gente quer mais / Quer mais e melhor / É com a Dilma que eu vou". Pode-se afirmar, inclusive, que, em função da candidata à presidência da República (do PT) estar à frente nas pesquisas em relação ao candidato do PSDB que era apoiado por Beto Richa, e do então atual presidente da República apresentar tanta aceitação popular, há uma aproximação do jingle de Beto Richa com objetivos de atingir esse eleitorado; mesmo que no estado do Paraná ela não tivesse a maioria de votos, segundo resultados de pesquisas divulgados pela mídia. Recupera-se uma memória de que se tem que votar no candidato que está à frente nas pesquisas, resgata-se a ideia de ir onde a maioria está. Essas são possibilidades de efeitos de sentido dados pelo modo de discursivização do jingle.

No refrão de um dos jingles "Ah, Paraná, se enche de orgulho e veste essa camisa / ah, Paraná, pra governador, en quero Beto Richa", pode-se perceber um efeito de sentido interessante ao se utilizar a metonímia, ou seja, o emprego de uma palavra por outra pela sua ligação íntima, como parte do todo. $\mathrm{O}$ efeito esperado estaria no fato de as pessoas entenderem-se como parte deste território, o que as tornam ligadas ao Estado por meio de uma relação de poder. Ademais, encontra-se neste refrão o uso de verbos no imperativo "se enche de orgulho" e "veste essa camisa", expressão popular que quer dizer "se empenhar muito’ e quem se empenha, deseja e alcança o melhor, aqui com pressupostos de vestir a camisa do partido, do candidato e votar nele; mas também, ter orgulho de ser paranaense e vestir a camisa do Paraná que quer mudança, que quer um novo Paraná.

\subsection{Osmar Dias x Beto Richa}

A partir da análise dos jingles de cada candidato vários ethé determinados são encontrados, os quais se constroem na oposição com a produção de uma espécie de antiethos para o seu adversário. No caso de Beto Richa pode-se perceber pelos jingles um ethos de 'modernidade', que libertaria o Paraná do peso do fazer político tradicional, representado por seu adversário. Esse novo, moderno se revestiria ainda de 'coragem', 'experiência', 'competência', 'virtude', como a honestidade: "Tem coragem e experiência / Richa é filho desse chão / Tem história e competência pra mudar a direção" e "O Paraná está mudando, Tá soprando um outro vento, pra andar pra frente, pra cuidar da gente, um novo tempo, Tempo de ideias novas,". Trata-se, pois, de um discurso pautado no imaginário da modernidade que ressalta a eficácia da 
ação política para concretizar sonhos, juntando competência e vontade de agir.

Nos jingles de Osmar Dias, um ethos em evidência é o da 'unidade', mas fica marcado também um ethos de 'experiência', 'coragem' e 'simplicidade': "Quem vota Dilma, vota Osmar / Essa é a hora da união / Osmaré mais experiência, é amor no coração / tem a força que precisa pra cuidar do Paraná, ah no Osmar vamos votar" e "Osmar é do meu povão / conhece todo esse chão / vai ter jeitão arretado pra governar".

Charaudeau (2006, p. 165) destaca como uma das características do ethos de 'solidariedade' o saber ouvir, para ele isso denota "uma atitude de consideração para com os outros, seus problemas, seu sofrimento, mas também para com suas necessidades". E esse ethos fica marcado no jingle de Beto Richa em: "Um novo jeito de governar / Ouvindo o que o povo quer".

Enquanto o jingle de Osmar Dias fala em "Vai embora violência", o de Beto Richa "É Beto Richa pra crescer em paz". comprova o confronto entre ambos, mas mantendo os mesmos temas de campanha; característica bastante presente no discurso político: o diálogo com a agenda política, numa tentativa de colocar-se como "solução salvadora" (CHARAUDEAU, 2006, p. 91), o responsável pela ruptura (violência x paz) e o eleitor será responsável também por esse momento salvívico, que quer essa ruptura, fazendo isso através do voto. Além desses temas, comuns aos dois, nos jingles de Osmar Dias aparecem ainda educação, saúde e segurança. Já nos três jingles de Beto Richa fica explícito o valor da modernidade, marcado também pelo slogan de campanha - “Um novo Paraná”. Ao reforçar esse 'novo', essa mudança, o adversário é desqualificado para o cargo eletivo. Charaudeau (2006, p. 36), ao referir-se aos pré-construídos ideológicos, que nos anos 70 eram mais demarcados, particulares, em função da cisão entre direita/esquerda, afirma que "atualmente esse pré-construído é de uma ideologia que revoga as clivagens do passado e privilegia os valores universais" e isso ocorre nos jingles ao retomarem temas universais.

Os três jingles de Osmar Dias estão em $1^{\text {a }}$ pessoa do plural - 'nós', mas não é o candidato falando/cantando, mas um representante dos paranaenses que ganha voz para dirigir-se aos demais, apelando para esse envolvimento - 'nós juntos, unidos com o candidato podemos mais'. Tal discurso demonstra um efeito de sentido inclusivo de não deixar ninguém de fora, todos são responsáveis pela continuidade, pelo que já fora conquistado: "Paraná [todos nós] no rumo certo caminhando com Osmar". Esses 
destaques ao 'nós' estão fortemente marcados nos refrãos dos três jingles: 1) "Vamos Paraná, vamos / Vamos com Osmar, vamos / Vamos que vamos, vamos que vamos./ Vamos!!!”; 2) "Vamos juntos com o Osmar pra ganhar a eleição / vote 12, vote Osmar / Meteoro da Paixão [...]"; 3) "Nóis é do tipo animado / Paranaense esforçado / já temo um cara porreta pra votar / nóis tamo do mesmo lado / Vamos se unir pelo estado / Vamo votá no Osmar [...]."

Já nos jingles de Beto Richa, há uma mistura entre a $1^{a}$ pessoa do singular e formas que marcam a coletividade - "a gente"; "onde eu faço a minha vida"; "eu boto fe"; "feito por mim e por você"; "Um novo Paraná / É o que a gente quer / Um novo Paraná / É o que a gente faz. / Um novo Paraná / Com Beto Richa / A gente pode mais"; "Ah, Paraná, se enche de orgulho e veste essa camisa / ah, Paraná, pra governador, en quero Beto Richa /"; "O Paraná agora é Beto eu também sou, Todo mundo tá com Beto eu também tô, quero Beto Richa, meu governador?". Destaca-se, ainda, a forma de apelo: "ah, Paraná veste essa camisa" em um coletivo bem determinado, envolvendo todos os paranaenses, uma tentativa de união num grande sujeito, que suprime as diferenças individuais.

Uma característica dos jingles está relacionada às rimas, muitas vezes também marcadas nos discursos, pois a rima acrescenta melodia ao discurso, em que se dá entonação ao se pronunciar as palavras, há a preocupação em como a palavra vai soar ao ouvido do eleitor.

Para ambos os candidatos, o eleitor é visto como entendedor de que esta é a eleição que mudará os rumos de sua vida, desde que faça a escolha certa - escolha esta vinculada ao voto no candidato e no partido. Para um deles, o voto, a eleição proporcionará mudança e construção de um 'novo Paraná', que, então, necessariamente não pode estar bem; já para o outro propiciará a continuidade, já que o Paraná estaria no caminho certo, unido à candidata à presidência da República: "nóis tamo do mesmo lado / Vamos se unir pelo estado". O não dito constitutivo de cada discurso fica marcado na materialidade discursiva dos jingles: enquanto um propõe "um novo jeito de governar', visto que o 'velho' não serve mais, pois não está bom dessa forma, por isso a mudança para o 'novo'; o outro propõe o continuísmo, visto estar bem, logo não se deve arriscar uma mudança, pois está "no rumo certo".

$\mathrm{O}$ interdiscurso se apresenta de diversas formas no discurso dos candidatos, uma delas é a religiosidade, ao utilizar a palavra 'família', com a ressalva de que o termo 'família' pode estar relacionado com o partido e com os moradores do Paraná, ou, ainda, em "É Beto Richa, en boto fe". O interdiscurso aparece também quando ocorre a remissão ao jingle da candidata 
a presidente: "Todo mundo tá com Beto eu também tô," e "Quem vota Dilma, vota Osmar / Essa é a hora da união". No plano da textualização há a incorporação a músicas de sucesso entre determinado público que se objetiva seduzir ao voto, como a interpretada por Luan Santana, "Meteoro da paixão" composta por Sorocaba: "vote 12, vote Osmar / Meteoro da Paixão / Explosão de sentimentos pelo nosso Paraná, efeito possibilitado por essa formação discursiva.

Concernente à memória, também se observa um discurso preocupado em resgatar ações realizadas pelos candidatos ou comportamentos referentes a eles: "Um novo jeito de governar / Ouvindo o que o povo quer"; "Beto Richa já mostrou que faz". e "Paraná no rumo certo".

\section{Considerações Finais}

Os processos de produção, circulação e interpretação dos sentidos são históricos, portanto, não são apreendidos, em sua totalidade, em um único texto, em um único jingle. Mesmo assim, a interpretação completa dos sentidos de um texto ou de um conjunto deles é impossível, visto que se diz sempre a partir de um já-dito, ou seja, um texto retoma outro que ressoa a outro em uma infinitude. O sentido não está no texto, mas na relação que este mantém com quem o produz, com quem o lê ou ouve, com outros textos e com outros discursos possíveis. Logo, os sentidos se constroem na história. Os jingles desses sujeitos políticos, candidatos a governo do Paraná já mencionados apresentam sentidos neste momento histórico, nesta campanha política, apesar de apresentar regularidades próprias à formação discursiva político-eleitoral.

A produção de sentido dá-se no interior de um campo institucionalmente constituído como 'lugar de onde se fala' - campo político. Falar no interior desse campo significa inserir-se em uma 'formação discursiva' que determina o 'modo de dizer' e aquilo que 'se pode e se deve dizer' por meio dos jingles em uma época de campanha política. Mesmo sendo produzidos por agências, por compositores; características do candidato, do partido e mesmo do eleitor que se quer atingir são recomendadas, para não haver incoerências na campanha política, para haver uma interação entre o candidato e o eleitor, por meio de argumentos que levem o eleitor a 'vontade de agir' - votar nele.

A temática básica dos jingles (renovação/mudança x continuísmo) não apresenta um discurso original, mas regular em qualquer campanha 
política e é produzida a partir de outros discursos, por vozes dos políticos que os precederam, grupos políticos dos quais descendem os candidatos de hoje. Como consequência da caracterização do discurso político que se volta para a proposição de um projeto coletivo, há uma tentativa de construir a voz do povo, marcada por um 'nós', que inclui o sujeito candidato enquanto porta-voz dos eleitores. Concernente à memória, também se observa um discurso preocupado em resgatar ações realizadas pelos candidatos ou comportamentos referentes a eles, bem como o tempo de experiência política e a idade de ambos - novo x velho.

A maneira como políticos que disputam uma vaga demonstram a preocupação de agradar os eleitores, de tentar atender seus anseios a fim de conseguir o voto e fazer com que eles (os eleitores), como sujeito assujeitados ao discurso, participem desse processo, confirma a política como troca de favores entre candidato e eleitor. O eleitor quer que seus interesses e prioridades sejam atendidos e o candidato quer conquistar o eleitor por meio daquilo que mais se aproxima de seus anseios: a mudança, um 'novo Paraná' para aqueles que acham que está ruim ou o continuísmo para aqueles que acham que está bom. A representação que os candidatos fazem do eleitor tem como propósito conseguir uma maior aproximação deste, ser bem-visto, admirado, provocar um sentido positivo no eleitor e, assim, obter o retorno pelo voto. Confirma-se também que para os candidatos, o eleitor não é meramente um ouvinte, mas um sujeito que reage diante dos programas eleitorais, por meio dos jingles ouvidos pela TV ou rádio.

A ideologia se materializou nos jingles dos candidatos quando se observaram as palavras 'campo' e 'cidade', não colocando distinção entre um e outro. Outro fator que destaca a ideologia dos dois candidatos foi pela posição de ambos; um deles em concordância com a candidata à presidência, logo propõe a continuidade; e o outro candidato da oposição que pretende ouvir "o que o povo quer" e tendo como preocupação mostrar-se sem envolvimentos em escândalos ou corrupção: "Mais trabalho e transparência". Além disso, os jingles apresentam os candidatos como políticos que se destacam pela: coragem, experiência, competência, trabalho, respeito, proteção, amor, ânimo, esforço, união.

Os jingles foram tentativas de persuadir o eleitorado, a fim de conquistar o voto, provocando nos eleitores uma memorização sobre o candidato. $\mathrm{O}$ que estava sendo dito por meio dos jingles foi ao encontro daquilo que os sujeitos políticos imaginaram que o eleitor quisesse ou precisasse 
ouvir, para aderir ao voto, procedimento que se constitui como uma estratégia propriamente dita, mesmo que esses candidatos estivessem assujeitados às coerções do campo político, submetendo-se a determinada estratégia do marketing eleitoral, porque estivesse pautada no imaginário popular e enraizada na história.

Os jingles fazem parte das estratégias políticas de persuasão que integram a campanha dos candidatos e pretende-se envolver o eleitor, no espaço entre o dito e o não dito, para fazer crer que tal candidato é o melhor e por isso convencer, via linguagem, a votar nele, conferindo a quem assim o fizer status de conquista, de vitória.

\section{Referências}

ACHARD, P. et al. O papel da memória. Tradução e introdução José Horta Nunes. Campinas: Pontes, 1999.

BARONAS, R. L. Análise do discurso: apontamentos para uma história da noção-conceito de formação discursiva: São Carlos: Pedro \& João, 2007.

CARVALHO, M. A. S. Arquitetura discursiva e efeitos de liberdade em um site de relacionamentos pessoais. In: ROMÃO, L. M. S.; GASPAR, N. R. (Orgs.). Discurso midiático: sentidos de memória e arquivo. São Carlos: Pedro \& João, 2008.

CHARAUDEAU, P. Discurso politico. Tradução Fabiana Komesu e Dilson Ferreira da Cruz. São Paulo: Contexto, 2006.

COURTINE, J.-J. Metamorfoses do discurso político: derivas da vida pública. Organização, seleção e tradução C. Piovezani Filho e N. Milanez. São Carlos: Clara Luz, 2006.

COURTINE, J.-J. Análise do discurso político: o discurso comunista endereçado aos cristãos. São Carlos: EdUFSCar, 2009.

DOLHNIKOFF, L. Jingles de Dilma, Serra e Marina: mais do que mero marketing. 24 jun. 2010. Disponível em: <http://sibila.com.br/cultura/ jingles-de-dilma-serra-e-marina-mais-do-que-mero-marketing/3795>. Acesso em: 23 dez. 2010. 
ORLANDI, E. P. Terra à vista. Discurso do confronto: velho e novo mundo. São Paulo: Cortez; Campinas: Editora da Unicamp, 1990.

ORLANDI, E. P. As formas do silêncio: no movimento dos sentidos. 3. ed. Campinas: Editora da UNICAMP, 1995.

PÊCHEUX, M. Papel da memória. In: ACHARD, P. et al. Papel da memória. Tradução e introdução de José Horta Nunes. Campinas: Pontes, 1999.

PÊCHEUX, M. O discurso: estrutura ou acontecimento. 5. ed. Tradução Eni Puccinelli Orlandi. Campinas: Pontes, 2008.

PÊCHEUX, M. Semântica e discurso: uma crítica à afirmação do óbvio. Tradução Eni Puccinelli Orlandi et al. 4. ed. Campinas: Editora da Unicamp, 2009.

PÊCHEUX, M. Análise automática do discurso (AAD-69). In: GADET, F.; HAK, T. (Orgs.). Por uma análise automática do discurso. Uma introdução à obra de Michel Pêcheux. 4. ed. Tradução B. Mariani et al. Campinas: Editora da Unicamp, 2010.

RABAÇA, C. A.; BARBOSA, G. G. Dicionário de comunicação. São Paulo: Ática, 1987.

RUBIM, A. A. C.. Comunicação e política. São Paulo: Hacker, 2000. 